\title{
Body odour disgust sensitivity predicts authoritarian attitudes.
}

Marco Tullio Liuzza ${ }^{1,2}$, Torun Lindholm ${ }^{1}$, Caitlin B. Hawley ${ }^{1}$, Marie Gustafsson Sendén ${ }^{1}$, Ingrid Ekström $^{1}$, Mats J. Olsson ${ }^{3}$ and Jonas K. Olofsson ${ }^{1,4^{*}}$

${ }^{1}$ Department of Psyhology, Stockholm University, Stockholm, Sweden, ${ }^{2}$ Department of Surgical and Medical Sciences, "Magna Graecia” University of Catanzaro, ${ }^{3}$ Division of Psychology, Department of Clinical Neuroscience, Karolinska Institutet, Stockholm, Sweden, and ${ }^{4}$ Swedish Collegium of Advanced Study, Uppsala, Sweden.

* Corresponding author: Jonas K. Olofsson, jonas.olofsson@psychology.su.se

Word count: 10,006

Document details: version 08/08/2017

\begin{abstract}
Authoritarianism has resurfaced as a research topic in political psychology, as it appears relevant to explain current political trends. Authoritarian attitudes have been consistently linked to feelings of disgust, an emotion that is thought to have evolved to protect the organism from contamination. We hypothesized that body odour disgust sensitivity might be associated with authoritarianism, as chemo-signalling is a primitive system for regulating interpersonal contact and disease avoidance, which are key features also in authoritarianism. We used wellvalidated scales for measuring body odour disgust sensitivity (BODS), authoritarianism, and related constructs. Across two studies, we found that BODS scores explained the positive relationship between general disgust sensitivity and authoritarianism. In a third study, we showed a positive association between BODS scores and support for Donald Trump, who, at
\end{abstract}


the time of data collection, was a presidential candidate with an agenda described as resonating with authoritarian attitudes. Authoritarianism fully explained the positive association between BODS and support for Donald Trump. Our findings highlight body odour disgust as a new and promising domain in political psychology research. Authoritarianism and body odour disgust sensitivity might be part of the same disease avoidance framework, and our results contribute to the growing evidence that contemporary social attitudes might be rooted in basic sensory functions.

\section{Introduction}

Recent findings have suggested that human behaviour is governed by a "behavioural immune system" [BIS, 1, 2, 3], a set of psychological mechanisms that presumably evolved in order to a) detect cues of pathogen threats to health and survival, b) activate the appropriate affective and cognitive responses to such threats, and c) trigger the relevant avoidance behaviours [4]. Disgust is a pervasive emotion that might have thus evolved as a defence mechanism to protect the body from contamination by potentially harmful substances [5] and thus disgust plays a pivotal role in the behavioural immune system[6].

Disgusting substances (e.g., feces, mucus and wounds) often contain pathogens [7]. Disgust is, however, also elicited by noncontagious cues, such as physical, moral or sexual deviations, suggesting that an overly sensitive behavioural defence creates physical and social distance to others who are perceived as carrying even the slightest risk of contagion leading to social stigmatization [8].

Disgust may thus underlie avoidance behaviours towards individuals and groups that are perceived as foreign, strange, morally deviant, or norm violating [9, 10]. For instance, Faulkner and colleagues [11] found that higher levels of pathogen salience and perceived vulnerability to disease [12] predicted negative attitudes towards unfamiliar outgroups. 
In fact, feelings of disgust have been consistently linked to the stigmatization of ethnic [10, 13] and sexual minorities [14]. On a cross-national level, the risk of being exposed to parasites was associated with cultural differences in the endorsement of traditional values, conformism and in the emphasis on the psychological distinction between ingroup and outgroup $[15,16]$. From a behavioural immune system perspective, prejudice can be seen as a social discriminatory behaviour partly motivated by the fact that pathogens represent an invisible threat, and individuals with high levels of disgust sensitivity might be more likely to avoid foreign people, and to promote policies that avoid the contact with them, because they are perceived as potentially spreading unfamiliar pathogens, different hygienic or food habits [17]

So-called right-wing authoritarianism is a relatively common and stable ideological attitude [18-20] favouring a rigid social order, designated roles for different genders and ethnic groups, and a punitive attitude to perceived social, legal, and moral transgressions [21]. Such authoritarianism is viewed as an ideological expression of being highly vigilant to perceived threats [22]. Of particular interest from the behavioural immune system framework, individuals with authoritarian attitudes report higher disgust sensitivity, and higher physiological reactivity to disgust-evoking and aversive images [23]. This has been interpreted as suggesting that authoritarianism could be characterized as a disease avoidance mechanism, because authoritarianism would motivate less exposure to unfamiliar environments and individuals, and thus to less pathogenic threat [24].

Indeed, Navarrete and Fessler found that disgust sensitivity and perceived vulnerability to disease correlates with ethnocentrism [25]. Since disgust helps to prevent contamination [26], cultures with a high level of exposure to pathogens may also be more socially conservative [16]. The investigation of the link between disgust and politically ideology has captured the attention of political scientists [27], who are increasingly recognizing the role played by 
basic emotions in shaping political discourse. Hatemi and McDermott [28] suggested that one of the most plausible mediating factors in relating ideology to disgust might be the higher emphasis that conservatives place on moral 'purity', which is associated with disease avoidance concerns [29].

Smells and tastes are arguably the most potent disgust signals, and, accordingly, it has been theorized that moral disgust is intimately linked to chemoreception [30]. Environmental cues of infectious risk are often mediated by malodours, rather than by visual cues [31, 32], and cross-cultural investigations show that odours, and body odours in particular, are among the most universal triggers of disgust [33]. Moreover, following experimental induction of an inflammatory agent, body odours become more aversive to the perceiver [34]. Indeed, pathogenic processes can dramatically influence volatile organic compounds of the human body [35]. Olfaction is thus a potent cue system for disease risk. Bodily substances such as sweat, saliva and faeces are considered among the most potent triggers of disgust [33] and are indeed often fraught with pathogens [6].

When exposed to pathogen-related body odours (e.g., faeces), people report being more willing to pursue pathogen avoidant behaviours (e.g., using a condom during sex) [36]. Disgust-evoking odour stimulation was shown to amplify the severity of moral condemnation of norm violations [37]. Furthermore, a genome-wide analysis on the possible genetic determinants of ideology has suggested that differences in a DNA region that includes several genes related to olfaction, vary systematically across liberals and conservatives [38].

We hypothesized that body odour disgust sensitivity would be linked to social attitudes that favour traditionalism and prevent contact with outgroups, and more generally, with groups perceived as deviant. Specifically, we predicted that higher levels of body odour disgust sensitivity would be associated with a more authoritarian disposition. Furthermore, we predicted that individuals with higher levels of body odour disgust sensitivity would show a 
preference for the political candidate in the US Presidential election 2016 that appeared to attract the sympathies of authoritarian participants. Thus, in studies 1 and 2, we tested whether scores on the recently developed Body Odour Disgust Sensitivity (BODS) scale would have a positive relationship with authoritarianism, independently from other general disgust sensitivity scales that do not focus on body odour disgust. We recently showed that BODS scores are a good indicator of disgust responses to actual body odours, and thus BODS is particularly useful in survey-based studies [39]. While the BODS can be used as either a unidimensional construct (overall body odour disgust) or a two-factorial scale (body odour disgust for self vs. others), these two factors are highly correlated and in most cases they show similar patterns of convergent and discriminant validity when compared to other scales [40]. We thus chose to initially use the scale as a uni-dimensional construct.

In study 3, we took advantage of the imminent US Presidential election 2016 to test the hypothesis that high BODS scores would be related to political sympathies. Specifically, BODS was hypothesized to predict positive attitudes towards Donald Trump, a then presidential candidate whose campaign message had been characterized as authoritarian [41]. In all studies, we used Amazon Mechanical Turk for data collection, a method that has some benefits over laboratory experiments, including that large amounts of data can be rapidly collected online from geographically distributed individuals. Even though samples recruited through Amazon Mechanical Turk (M-Turk) may differ from the general population [42], M-Turk samples have been shown to be more diverse and representative than common convenience samples (e.g., college students) typically used in psychological research [43, 44]. Most importantly, for the purpose of the present study, data from M-Turk studies have been shown to be both psychometrically valid [45], and a valid tool for research on political ideology [46]. Furthermore, we note that our studies were designed with the primary aim to assess the asso- 
ciations between body odour disgust and specific social attitudes, and not to characterize any specific group of voters.

\section{Study 1}

\section{Method}

\section{Participants}

Based on effect sizes reported in previous research [47] we aimed at collecting data from at least 160 participants in order to gain a power of .80 . In order to maximize the variability of our sample, we did not restrict our recruitment to any particular geographical region. Eligible participants were Mechanical Turk workers who had a prior approval rate of at least $85 \%$. The study was launched on the 29th of April 2013, and all data were collected in about 4 days. The final sample included 201 participants ( 83 females; age, $\mathrm{M}=33.13, \mathrm{SD}=10.32$ years). Participants were paid $\$ 0.50$ each for their participation.

Three participants (1.5\%) had no higher education, $12(6 \%)$ received a High school diploma or equivalent, 34 (17\%) attended to some college, 9 (4.5\%) received an Associate degree, 106 (52.7\%) a Bachelor degree, 33 (16.4\%) a Master degree, 2 (1\%) a Professional degree and $2(1 \%)$ a Doctorate degree. In terms of race/ethnicity, 99 (49\%) defined themselves as Asian (mainly due to a high degree of participation from Mechanical Turk workers based in India), $86(43 \%)$ as White, $10(5 \%)$ as Black/African American and $5(2.5 \%)$ as Latino/Hispanic.

Measures

The BODS includes six body odour sources (breath, axillary sweat, feet, feces, urine, and gas), each of which appears in two different contexts: Internal source (own-smell), and External source (the smell of an unfamiliar person). The BODS displays excellent internal consistency, strong convergence with existing disgust sensitivity scales, and a recent study 
showed that BODS, compared to the most commonly used disgust scales, had a stronger relationship with perceived vulnerability to disease [40]. Furthermore, BODS scores correlated strongly with self-reported disgust reactivity to sweat bio-samples, suggesting BODS is a valid assessment of body odour disgust [39].

The BODS scale items can be found in the Material component on OSF: https://osf.io/4w2nh/?view_only=2dcc174166a747fe8078a8f02f143f22. In each of the 12 scenarios, participants rate to what extent the scenario elicits disgust, using a scale that ranges from 1 (not disgusting at all) to 5 (extremely disgusting). A high level of internal consistency was obtained for the BODS (Cronbach's alpha $=.93$ ).

We included a set of well-validated scales for measuring individual differences in social attitudes. We used the Right-Wing Authoritarianism scale, a well-established assessment measuring authoritarian dispositions (RWA[21]). We used a validated version with fifteen items that did not reference specific minority populations, and hence avoided conflating authoritarianism with specific prejudice [48]. Participants reported their level of agreement with each statement on a 7-point scale ranging from 1 (totally disagree) to 7 (totally agree). We included the Three Domains of Disgust Scale (TDDS, [49]), a scale that measures three distinct domains of disgust sensitivity (moral, sexual, and pathogen). Each factor is represented by seven items measured on a one to seven-point scale, ranging from 0 (not at all disgusting) to 6 (extremely disgusting). For all of these measures, a high internal consistency was obtained (Cronbach's alpha $>.80)$.

As olfactory disgust is assumed to be a form of pathogen disgust, we included only the TDDS pathogen subscale as a control (TDDS-pat, e.g., "Sitting next to someone who has red sores on their arm"), in order to provide the closest and most relevant comparison to body odour disgust. Instead, subscales measuring sexual disgust (e.g., "Watching a pornographic video") and moral disgust (e.g., "A student cheating to get good grades") were not included 
because they correlate only weakly with pathogen disgust [49]. While those with an authoritarian disposition might often react with disgust to moral [50] and sexual norm violations [51], these issues were not of relevance here. Instead, we focused on pathogen threat, which is not a topic included in authoritarianism assessments. It should be noted that the RWA scale used in this study have at least eight items that are somewhat related to sexuality (e.g., "Gods laws about abortion, pornography and marriage must be strictly followed before it is too late, violations must be punished") morality and sexuality (e.g. "Facts show that we have to be harder against crime and sexual immorality, in order to uphold law and order") or morality in general (e.g., "There are many radical, immoral people trying to ruin things; the society ought to stop them"), but no items that are directly related to pathogen concerns. Trivial effects due to thematic overlap would thus not influence our focus on relationships between RWA and pathogen-related variables. But olfaction might play a role in pathogen avoidance, and thus pathogen disgust was considered the most well suited and strict control measure when investigating the unique link between olfactory disgust and authoritarianism.

Finally, right-wing authoritarianism must not be conflated with political conservatism. For this reason, in addition to RWA, participants were also presented with three items to assess their degree of liberalism vs. conservatism in the social, moral or fiscal domains. These items were adapted from Helzer and Pizarro [52] ("When it comes to social/moral/fiscal issues, how would you describe your political attitudes?"). Participants reported their responses on three separate 7-point scales ranging from 1 (very liberal) to 7 (very conservative). The responses were subsequently reverse-coded to make their interpretation coherent with the other scales (i.e., high scores $=$ high level of conservatism).

Other measures of self-reported attitudes towards gender roles, hygiene, personality, ideological affiliation and self-reported measures of olfactory functions were collected for the purpose of another study and therefore not included in the current analysis. However, all items 
and data from the original survey can be retrieved online on the Open Science Framework (OSF) repository at the following link:

https://osf.io/c8xjy/?view_only=2dcc174166a747fe8078a8f02f143f22.

Bayesian inferences on zero-order correlations were performed using the free statistical package JASP [53] using both Pearson' $r$ and Kendall's tau, as the latter is better suited for variables that are not normally distributed. This procedure allows us to assess the relative evidence (Bayes Factor) in favour of the alternative $\left(\mathrm{BF}_{10}\right)$ or the null $\left(\mathrm{BF}_{01}\right)$ hypothesis. We chose this approach because it allows to compare the relative strength of evidence in favour of competing hypotheses (i.e., H0: $\rho=0$ vs. H1: $\rho \neq 0$ ) [54]. Instead of the JASP default prior (width $=$ $=1$ ) on the alternative hypothesis regarding the parameters $r h o$ and tau, we used a prior of width $=0.5$, because $68 \%$ of the coefficients sampled from that distribution would fall between -.25 and .25 , similarly to a normal distribution cantered on zero and with standard deviation of .25 . The choice of this value was informed by the overall meta-analytic effect size $(\approx .25)$ found for the relationship between BIS measures and Social Conservatism [24]. We interpreted and labelled the sizes of BFs according to the recommendations of Raftery [55] as referred to by [56].

\section{Results}

In our Electronic Supplementary Material (ESM), we provide descriptive results for all variables, along with their distributions.

Consistent with our predictions, we found very strong evidence [57] in favour of the hypothesis that RWA correlates with pathogen-related disgust (TDDS-pat, Pearson's $r=.32, \mathrm{BF}_{10}=$ 4,620 ) and olfactory body odour disgust (Pearson's $r=.39, \mathrm{BF}_{10}=995,802$; see zero-order correlations in Table 1 and Figure 1). 
Insert Table 1 here

Insert Figure 1 here

To establish the specificity of BODS in predicting RWA, we ran a series of Bayesian hierarchical multiple regression where the parameters were estimated via quadratic approximation through the maximum a posteriori (MAP) function implemented in the package rethinking [58].

Following the analytical strategy proposed by Richard McElreath [59] we used the Widely Applicable Information Criterion (WAIC, [60]) to compare and average across models to account for uncertainty across models [58]. In fact, the WAIC can be conceptualized as an approximate Bayesian cross-validation [59].

We defined four models that included either the BODS, the TTD.pat, both, or neither of the two (See Table 2). We always included education, ethnicity, gender and age as possible confounding variables. All the variables were standardized to ease interpretability and parameter estimation. Priors for the BODS and TDD.pat coefficients were normally distributed centered on 0 and with $\mathrm{SD}=.25$, consistent with the overall meta-analytic effect size $(\approx$ .25) found for the relationship between BIS measures and Social Conservatism [24]. This procedure makes it unlikely to have an estimate that deviates too much from the typical effect size found in the field. Priors for coefficients of the covariates of no theoretical interest (i.e., demographic variables) were normally distributed centred on 0 and with $\mathrm{SD}=1$, reflecting our higher level of uncertainty on these parameters. Finally, we computed means and $95 \%$ Percentage Intervals (PIs) from the posterior predictive distributions in order to compute the 
predictive posterior probabilities of the estimated parameters [59].

The model comparison showed that the model that includes only the BODS, controlling for the confounding variables, was the most accurate (see Table 2).

Insert Table 2 here

Congruent with our hypotheses, BODS scores were related to RWA even when averaging across models, as shown by the average BODS coefficient and related Percentage Intervals (CIs) from the posterior predictive distributions $(B=.14,95 \% \mathrm{PI}=[\mathrm{LL}=0, \mathrm{UL}=$ $.30])$. The results hence show a link between RWA and BODS that was not shared by another, non-olfactory pathogen disgust assessment.

\section{Study 2}

After establishing a specific association between body odour disgust sensitivity and authoritarianism, we sought to replicate and extend these findings in a sample of participants that was geographically restricted to the USA. Study 2 thus aimed to validate the hypothesized association of BODS and authoritarianism, and to compare the predictive utility of BODS to some other measures that have been previously associated with authoritarianism (see [24] for a review). In particular, we focused on overall disgust sensitivity [61, 62] and germ aversion, assessed with the germ aversion subscale of the perceived vulnerability to disease scale [63].

\section{Method}

Participants

Based on effect sizes reported in previous research [47] we aimed at collecting data from 
about 160 US participants in order to gain a power of .80. Eligible participants were Mechanical Turk workers who were based in the USA and who had a prior approval rate of at least $85 \%$. The study was launched on the 25th of March, 2015, and all data were collected in about 6 days. Participants were paid $\$ 0.50$ each for their participation.

Six participants (3.6\%) failed to respond correctly to the control question ("To let us know that you're reading carefully, please check "Other" below and write "I read it" in the text box) and were therefore removed from further analyses. The final sample consisted of 159 participants ( 75 females; age, $\mathrm{M}=35.11, \mathrm{SD}=11.88$ years).

Three participants $(2 \%)$ did not receive any higher education, $12(8 \%)$ received a High school diploma or equivalent, 45 (28\%) attended some college, $22(14 \%)$ received an Associate degree, 55 (35\%) a Bachelor degree, 17 (11\%) a Master degree, 4 (3\%) a Professional degree and $1(1 \%)$ a Doctorate degree. In terms of race/ethnicity $133(84 \%)$ defined themselves as White, $10(6.3 \%)$ as Asian, $15(9.5 \%)$ as Black/African American and 8 (0.5\%) as Latino/Hispanic.

\section{Measures}

In this study we used some of the measures used in Study 1 (RWA, BODS, and TDDSpat) and added the Disgust Scale Revised (DS-R) and the Perceived Vulnerability to Disease (PVD). All of these measures displayed a Cronbach's alpha of at least .79. As in Study 1, our analysis strategy was to investigate the specificity and fit of a model in which BODS predicted authoritarianism.

The DS-R [62] is an updated version of the most well established scale to measure individual differences in disgust sensitivity [61]. Participants indicated their agreement with 13 statements (e.g., "I never let any part of my body touch the toilet seat in a public washroom”) on a 7-point scale ranging from 1 (strongly disagree) to 7 (strongly agree), and rated how disgusting they would find 12 specific situations (e.g., "You see maggots on a piece of meat 
in an outdoor garbage pail") on a 7-point scale ranging from 1 (not disgusting) to 7 (very disgusting). Although the scale includes a subscale assessing contamination-related disgust, it showed suboptimal internal consistency (Cronbach's alpha $=.55)$, with a subsequent increase in the noise of the measurement and loss in statistical power [64]. Furthermore, while the TDDS subscales are theoretically motivated [49], the subscales of the DS-R are data-driven [62] and their boundaries are not always well-defined. For instance, while items such as item 4 ("I never let any part of my body touch the toilet seat in a public washroom") are surely the expression of a strong concern of contamination, some items that are categorized as "core disgust" (e.g., item 18, "You are about to drink a glass of milk when you smell that it is spoiled") or "animal reminder" (e.g. item 11, "It would bother me tremendously to touch a dead body") are nonetheless likely motivated by pathogen avoidance concerns. We thus chose to use data from all items of the DS-R (Cronbach's alpha $=.86$ ), as it constitutes the most well established general measure of disgust.

The PVD is a 15-item questionnaire, divided in two subscales, assessing individuals' discomfort in situations that imply a high likelihood of pathogen transmission (Germ Aversion subscale, e.g., "I don't like to write with a pencil someone else has obviously chewed on") and individuals' explicit beliefs that they are susceptible to contracting infectious diseases (Perceived Infectability subscale, e.g., "I am more likely than the people around me to catch an infectious disease"). Participants indicated their agreement on a 7-point scale $(1=$ strongly disagree; $7=$ strongly agree, Cronbach's alpha $=.88)$. We focused our analysis only on the Germ Aversion avoidance subscale (Cronbach's alpha $=.79$ ), as this is the subscale that relates more closely to the BIS [24].

Other measures of self-reported attitudes towards gender roles, hygiene, personality and ideological affiliation and self-reported measures of olfactory functions were collected to the purpose of another study and therefore not included in the current analysis. All the items 
and the data from the original survey can be retrieved online on the OSF repository at the following link: https://osf.io/zjpy4/?view_only=2dcc174166a747fe8078a8f02f143f22.

Bayesian inferences on zero-order correlations were performed using the free statistical package JASP [53] using both Pearson' $r$ and Kendall's tau, as the latter is better suited for variables that are not normally distributed. This procedure allows us to assess the relative evidence (Bayes Factor) in favour of the alternative $\left(\mathrm{BF}_{10}\right)$ or the null $\left(\mathrm{BF}_{01}\right)$ hypothesis. We chose this approach because it allows to compare the relative strength of evidence in favour of competing hypotheses (i.e., H0: $\rho=0$ vs. H1: $\rho \neq 0$ ) [54]. Instead of the JASP default prior prior $($ width $=1)$ on the alternative hypothesis regarding the parameters rho and tau, we used a prior of width $=0.5$, because $68 \%$ of the coefficients sampled from that distribution would fall between -.25 and .25 , similarly to a normal distribution cantered on zero and with standard deviation of .25 . The choice of this value was informed by the overall meta-analytic effect size $(\approx .25)$ found for the relationship between BIS measures and Social Conservatism [24].

We interpreted and labelled the sizes of BFs according to the recommendations of Raftery [55] as referred to by [56].

\section{Results}

In our ESM, we provide descriptive results for all variables, along with their distributions.

Replicating findings from Study 1, we found positive evidence in favour of the hypothesis that RWA correlates with BODS (Pearson's $r=.24, \mathrm{BF}_{10}=14.44$ ) and weak evidence in favour of the correlation between RWA and general disgust sensitivity as measured by DS-R (Pearson's $r=.19, \mathrm{BF}_{10}=2.5$; see Table 3 and Figure 2). 
Insert Table 3 here

Insert Figure 2 here

In order to test the best predictor of authoritarianism among the two disgust measures that were most clearly related to RWA (BODS, DS-R), we entered these variables - along with age, gender, education and ethnicity — in a series of Bayesian hierarchical models compared and averaged through WAIC as described in Study 1. The model comparison showed that there is a certain amount of uncertainty (dSE is bigger than dWAIC) on what should be considered the best model in terms of WAIC among the ones that included the BODS, the DS-R, or both (see Table 4). Although the posterior predictive distributions PIs of both DS-R and BODS included zero in the averaged model, it should be noted that they correlate substantially and thus it might be that their joint contribution is crucial in explaining variance in RWA but neither of the two seem to be a strong independent predictor of authoritarianism when controlling for the other.

Insert Table 4 here

\section{Study 3}

In studies 1 and 2 we showed a consistent relationship between body odour disgust sensitivity and authoritarianism. We also found that BODS performs better than other measures of disgust, such as TDDS-pat, DSR and PVD in predicting authoritarianism. A possible limitation from studies 1 and 2 is that these studies were conducted on the same samples 
used in a prior validation study [40], so we felt compelled to replicate the results in a new sample. Furthermore, the US Presidential elections 2016 offered a unique opportunity to test the ability of the BODS to predict attitudes towards the political candidates, in particular Donald Trump, who was described as having a particularly authoritarian message [41].

We hypothesized there would be a positive correlation between BODS scores and positive attitudes towards Trump, but we also expected this relationship to be explained by RWA, a variable that we hypothesized would be positively associated with both BODS scores and support for Trump. We expected this mediating role of RWA to not be shared with measures that reflect an endorsement of social dominance or inequality [22], such as Social Dominance Orientation (SDO) $[65,66]$. While RWA and SDO are positively correlated in the population, SDO uniquely captures the tendency of some individuals to "step on others to get ahead". Of importance to our study, social dominance typically requires direct social interactions, which does not reduce pathogen threat, in contrast to RWA, which appeals to authorities to provide a rigid social order.

\section{Method}

\section{Participants}

We established a sample size that would allow us to detect, with $80 \%$ power, a relationship between RWA and BODS that was half as strong as that found on average in Studies 1 and $2(r=.16)$. A power analysis yielded at least 313 participants. To prevent the possible impact of high drop-out rates, our survey was set to aim to 400 participants. Eligible participants were Mechanical Turk workers who were based in the USA and who had a prior approval rate of at least $85 \%$.

Study 3 was launched on Oct 12th, 2016 (about one month prior to the presidential election), and all data were collected in about 24 hours. A final sample of 391 participants 
(219 females; age, $\mathrm{M}=37.45, \mathrm{SD}=12.19$ years) was recruited from the United States using through Amazon Mechanical Turk. Participants were paid $\$ 0.50$ each for their participation. Three participants (1\%) did not receive any higher education, $45(12 \%)$ received a High school diploma or equivalent, 95 (24\%) attended to some college, $46(12 \%)$ received an Associate degree, 141 (36\%) a Bachelor degree, 49 (13\%) a Master degree, 5 (1\%) a Professional degree and 7 (2\%) a Doctorate degree. In terms of race/ethnicity 305 (78\%) defined themselves as White, $23(6 \%)$ as Asian, $22(6 \%)$ as Black/African American, $4(1 \%)$ as native American and 1 (less than 1\%) as Latino/Hispanic.

\section{Measures}

We included the RWA and BODS assessments similarly to Studies 1 and 2, and added Social Dominance Orientation (SDO) as a control measure. All of these measures displayed a Cronbach's alpha of at least .93 . The SDO measures the tolerance for inequality among social groups and in this study we used a well-established 16-item version [65]. Participants were asked to indicate how they felt about each of the sixteen statements (e.g., "It's OK if some groups have more of a chance in life than others.") on a 1 ("very negative") to 7 ("Very positive") Likert-type scale.

Additionally, in order to assess participants attitudes towards each of the five then presidential candidates (Donald Trump, Hillary Clinton, Gary Johnson, Jill Stein and Darrel Castle), we adapted items from the American National Election Studies [67] that assessed, though a Visual Analogue Scale (VAS) from 0 to 100 :

- Two items assessing the Emotional Thermometer towards each: a) "The US Presidential elections are approaching. How would you feel about each candidate becoming the next president of the USA?" with a response setting ranging from 0 ("Extremely negative") to 100 (Extremely positive"), b) "We'll show the name of a person or group and we'd like you to rate that person or group using something we call the feel- 
ing thermometer" with a response setting ranging from 0 ("Very cold or unfavourable feeling") to 100 ("Very warm or favourable feeling").

- One item assessing participants voting intentions (i.e., "How likely are you to vote for each presidential candidate?") with a response setting ranging from 0 (“Extremely unlikely") to 100 ("Extremely likely").

We narrowed our analysis down to the two candidates who were leading the polls at the time when the study was conducted, namely Hillary Clinton (Democrat) and Donald Trump (Republican). We found that the attitudes and voting intentions measures displayed high internal consistency (Cronbach's alphas $\geq .96$ ), and collapsed them to an overall "support" variable for each candidate.

Other measures of self-reported attitudes towards gender roles and ideological affiliation were collected to the purpose of another study and therefore not included in the current analysis.

Method and statistical analysis package were identical to those used in Study 2. Our prior of width $=0.5$ was based on the overall meta-analytic effect size $(\approx .25)$ found for the relationship between BIS measures and Social Conservatism [24].

We interpreted and labelled the sizes of BFs according to the recommendations of Raftery [55] as referred to by [56].

\section{Results}

In our ESM, we provide descriptive results for all variables, along with their distributions.

Both RWA and SDO were related to positive attitudes towards Trump (see Table 5 and Figure 3, $\mathrm{BFs}_{10}>1,000,000$ ). Replicating findings from Studies 1 and 2, we found very strong evidence in favour of the hypothesis that BODS correlates with RWA (Pearson's $r=$ $\left..23, \mathrm{BF}_{10}=3,977\right)$. However, we also found positive evidence in favour of the absence of a 
relationship between the BODS and $\operatorname{SDO}\left(r=-.02, \mathrm{BF}_{01}=9.5\right)$. We found weak evidence in favour of the hypothesis that BODS correlates with positive attitudes towards Trump $(r=.13$, $\left.\mathrm{BF}_{10}=2.8\right)$. Although the evidence in favour of this relationship is weak, it should be noted that, when controlling for the other demographic variables through a Bayesian regression model and a narrower prior distribution of the parameters (the same as those used in Studies 1-2), the relationship between the BODS scores and attitudes towards Trump was found to be confidently above zero $(B=.17,95 \% \mathrm{PI}=[.08, .27])$. Overall, this result suggests that, when controlling for other possible confounding variables and having a prior belief that is informed by previous literature, we can confidently believe that attitudes toward Trump were positively related to BODS scores, given the data, although the effect size was small.

Insert Figure 3

Insert Table 5

We tested whether the coefficient of the relationship between SDO and BODS is smaller than the coefficient of the relationship between RWA and BODS even when taking other possible confounding variables into account. To this purpose, we fitted our data in a Bayesian regression model as in the previous analyses and computed the mean and PIs of the difference between coefficients from the posterior sample distribution. We found that the RWA is reliably more related to BODS than SDO (mean $B$ difference $=0.40,95 \%$ PIs $=$ $[0.22,0.59])$.

Finally, we conducted mediational analyses on the data from Study 3, through the mediation R package [68] using a quasi-Bayesian Monte-Carlo method based on normal ap- 
proximation [69], to test if the relationship between body odour disgust sensitivity and positive attitudes towards Trump was mediated by authoritarianism. As predicted, the results indicated that the relationship between BODS and attitudes towards Donald Trump was fully mediated by RWA (see Figure 4; 95\% CI $=[.075, .19)]$.

\section{Insert Figure 4}

\section{Discussion}

Although the Behavioural Immune System framework assumes a relationship between pathogen avoidance motives, and an orientation towards authoritarianism and social dominance [24], the role played by body odours has been largely overlooked [40]. Odours originating from the human body are among the most potent triggers of disgust and having a strong body odour is considered socially stigmatizing [70]. Prior work has established that a person's body odours contain information about their emotions $[71,72]$ and health [34] (see [73] for a recent review). Indeed body odours are affected by pathological processes [36] and we found that individual differences in disgust sensitivity to body odours are related to perceived vulnerability to diseases to a greater extent than individual differences in general disgust sensitivity [41].

Across three studies, we provided evidence that high levels of disgust sensitivity for body odours predicts authoritarian attitudes that imply resistance to social change and motivates separation of groups and individuals. Importantly, BODS does not positively relate to self-reported measures of conservatism when dissected into moral, social and fiscal aspects (Study 1), so the link to body odour disgust appears specific to authoritarianism, although the use of single item measures of ideology poses obvious reliability concerns. 
Although the size of the BODS-authoritarianism association is of small-to-medium size, its magnitude is in line with previous meta-analytical evidence $(0.21<r \mathrm{~s}<.36)$ on the relationship between BIS measures and social conservatism [74]. More generally, the effect sizes found in our three studies are consistent with the finding of a "meta-meta-analysis" summarizing 322 meta-analyses with more than 25,000 published studies in the field of personality and social psychology [75], which showed an average effect of $r=.21$. Furthermore, although the idea that unconscious motivations determine political attitudes is intriguing [76], they are arguably predominately driven by explicit processes, where socialization plays an important role (see [77] for a detailed review). Hence it is not surprising to see unconscious motivations explaining only a small portion of the overall variance when it comes to political attitudes.

Our observation that BODS relates more strongly to RWA than to SDO (Study 3) fits very well with the "dual process" framework proposed by Duckitt [22], and that assumes different underlying motivations for authoritarianism and social dominance orientation. According to this view, authoritarian motives arise from the perception of a social threat, described by the metaphor of the world as a dangerous place, and leads to the upholding of social order and tradition. In contrast, social dominance is prompted by the perception of the world as a competitive jungle, where it is justified to step on others to get ahead. Thus, authoritarianism might be more closely linked to avoidance, whereas social dominance would be linked to competitiveness. Indeed, that BODS and authoritarianism (but not social dominance) may co-vary because they can both be conceptualized as a defence against possible pathogen threats $[78,79]$, coherent with the behavioural immune system framework [17]. In support of this interpretation, recent work found that cultural differences in the level of exposure to pathogens are related to authoritarianism, but not to social dominance [80]. Moreover, it has been found that intergroup contact might decrease intergroup hostility prompted by 
authoritarian motives, but not intergroup hostility prompted by dominance motivations [81]. Similarly, we may speculate that familiarization with odours associated with foreign cultures may reduce prejudice in participants high in authoritarianism, but not in social dominance.

Only a few studies have investigated the relationship between disgust sensitivity and voting preferences [82]. In Study 3, we showed a weak relationship between disgust sensitivity to body odours and attitudes toward the Republican candidate Donald Trump. Importantly, this relationship is fully explained by authoritarian attitudes which were stronger among participants supporting Trump, a result that confirms the notion that in our study sample, Donald Trump was capable of attracting the sympathies of authoritarian voters [41]. In fact, it can be argued that Trump's firm stance against immigration, especially from groups viewed as culturally unfamiliar, might meet an implicit need of protection from pathogen threats from people perceived as either potential carriers of unfamiliar pathogens, or groups whose behaviours in disease-avoidance relevant behaviours (e.g., hygiene or food preparation) was perceived as deviant [17]. Our findings suggest that high reactivity to pathogen threats signalled by body odours is part of an ideological disposition towards authoritarian candidates, because of the link between disease avoidance and authoritarianism.

The reason why the behavioural immune system is often hyper-vigilant is because bacterial threats are often not detectable through visible cues [83], so the system acts in accordance with a "better safe than sorry" logic [84] to avoid contact with unfamiliar environments and groups [85]. In fact, meta-analytical evidence showed a consistent association between different manifestations of social conservatism and individual differences in the activation of the behavioural immune system [74], although none of the studies included in this metaanalysis had a special focus on body odours disgust. Considering the central role played by olfaction in preventing microbial hazards [86] and the observation that body odours can signal the presence of a disease [35, 87], it is perhaps not surprising that individual differences 
in body odour disgust sensitivity, reliably assessed with a well-validated questionnaire [39, 40] is indeed a predictor of authoritarianism, an attitude suggesting avoidance of unfamiliar groups.

There are limitations to this study. Most importantly, our samples are not randomly drawn from the population, but are based on voluntary engagement of individuals within the online community of Mechanical Turk workers. It is well-known that in most psychological studies, whites and liberals are over-sampled relative to conservatives and minority populations [42]. However, our results show $36 \%$ of participants supporting Trump over Clinton, at a time when Trump was polling at around $40 \%$ of the popular vote [88], indicating our sample was representative in this regard. Furthermore, Mechanical Turk samples are known to be more diverse than laboratory studies conducted at Universities. Future work should attempt to overcome the challenges associated with population-based sampling. A second limitation is that we did not measure disgust responses to actual odours, but used the body odour disgust scale (BODS) to probe differences in disgust sensitivity. However, we recently showed that BODS scores predict disgust responses to sweat samples [39], so our conclusions would likely generalize to situations involving odour stimulation.

Disgust sensitivity and authoritarian attitudes may vary as a function of parasite-stress $[16,80]$. In our sample we were unable to address the levels of pathogen stress of the environments where our respondents have been living. Future cross-national investigations would benefit from integrating predictors of authoritarianism in local environments.

Another possible limitation is that we lacked a measure of income, which is often associated with positive attitudes toward immigration [89]. Nevertheless, in our analyses, we controlled for education, which may be considered a good proxy of income and other lifestyle factors. 
There is increasing interest in the role of olfaction and disgust for social attitudes [27, $28,38,90]$. Our work complements these on-going efforts by providing a relevant measure (BODS) of the individual susceptibility for odour-evoked disgust and its links to social attitudes. This line of research might also further our understanding of how basic chemosensory processes might have evolved as triggers of disgust and social regulation mechanisms [78].

\section{Research Ethics}

The experimental procedures were approved by the Department of Psychology of the University of Stockholm and were carried out in accordance with the principles of the 1964 Declaration of Helsinki. Participants were informed on the general purpose of the study and provided their informed consent by continuing the survey (see materials stored on the OSF repository: https://osf.io/4w2nh/?view_only=2dcc174166a747fe8078a8f02f143f22).

\section{Data, code and materials availability.}

Materials, data, R scripts and JASP files for reproducing all the reported analyses and procedures are stored in the OSF repository, accessible at the address:

https://osf.io/4w2nh/?view_only=2dcc174166a747fe8078a8f02f143f22.

\section{Author contributions}

MTL, TL, MGS, CH and JKO designed the research. MTL, CH, IE and JKO performed the research. MTL, CH and JKO analysed the data. MTL, JKO, MJO, TL, MGS and $\mathrm{CH}$ wrote the manuscript. All authors approved the final version of the manuscript.

\section{Declaration of Conflicting Interests}


The authors declare that they had no conflicts of interest with respect to their authorship or the publication of this article.

\section{Funding}

This work was supported by research grants from the Swedish Research Council (2016-02018) and from The Lars Hierta Memorial Foundation (FO20160386) to MTL, research grants from the Swedish Research Council (421-2012-1125 and 2016-02742) to MJO, a Pro Futura Scientia VII fellowship and research grants from the Swedish Research Council (421-2012-806) and the Swedish Foundation for the Humanities and Social Sciences (M140375:1) to JKO.

\section{Figure and Table captions}

Table 1. Correlation matrix of study 1. Pearson's $r$ and Kendall's tau coefficients for the relationships among the variables measured on study 1 along with the Bayes Factor in favour of the alternative hypothesis $(\rho \neq 0$ and $\tau \neq 0)$ using a beta prior of width $=0.5$. BODS $=$ body odour disgust scale, TDD.pat = pathogen subscale of the three domains of disgust; bods = body odour disgust scale; RWA = right wing authoritarianism; SocCons = social conservatism; MorCons $=$ moral conservatism; FiscCons $=$ fiscal conservatism

Table 2. Study 1. Model comparison and posterior parameter estimates for the regression on RWA. The most accurate model is boldfaced. $B=$ standardized coefficients; SE $b=$ standard error of the coefficients; WAIC = widely applicable information criterion. dWAIC difference in WAIC from the best fitting model. DSE = standard error of the dWAIC. TDD.pat = pathogen subscale of the three domains of disgust; BODS = body odour disgust scale; EDU = education. 
Table 3. Correlation matrix of Study 2. Pearson's $r$ and Kendall's tau coefficients for the relationships among the variables measured on study 1 along with the Bayes Factor in favour of the alternative hypothesis $(\rho \neq 0$ and $\tau \neq 0)$ using a beta prior of width $=0.5$. TDD.pat $=$ Pathogen Subscale of the Three Domains of Disgust; BODS = Body Odour Disgust Scale; RWA $=$ Right Wing Authoritarianism; DSR = Disgust Sensitivity Revised; PVD.germ = Germ aversion subscale of the Perceived Vulnerability to Disease.

Table 4. Study 2. Model comparison and posterior parameter estimates for the regression on RWA. The most accurate model is boldfaced. $\mathrm{B}=$ standardized coefficients; $\mathrm{SE} B=$ Standard Error of the coefficients, WAIC $=$ Widely Applicable Information Criterion. dWAIC difference in WAIC from the best fitting model. $\mathrm{dSE}=$ Standard Error of the dWAIC. DS-R = Disgust Sensitivity - Revised; BODS = Body Odour Disgust Scale; Edu = Education.

Table 5. Correlation matrix of Study 3. Pearson's $r$ and Kendall's tau coefficients for the relationships among the variables measured on study 1 along with the Bayes Factor in favour of the alternative hypothesis $(\rho \neq 0$ and $\tau \neq 0)$ using a beta prior of width $=0.5$. BODS $=$ Body Odour Disgust Scale; RWA = Right Wing Authoritarianism; SDO = Social Dominance Orientation; Att. Clinton $=$ Positive attitudes towards Hillary Clinton; Att. Trump $=$ Positive attitudes towards Donald Trump.

Figure 1. Correlation matrix for Study 1 data. On the top right are displayed the scatterplots and regression fit lines for the relationships among the variables measured on Study 1. Along the diagonal are displayed the histograms and density plots for each of the variable. On the bottom left are displayed the posterior distributions for the parameter $\rho$ and $\tau$ under the alter- 
native hypothesis using a Beta prior of width $=0.5$ TDD.pat $=$ Pathogen Subscale of the Three Domains of Disgust; BODS = Body Odour Disgust Scale; RWA = Right Wing Authoritarianism; SocCons $=$ Social Conservatism; MorCons $=$ Moral Conservatism; FiscCons $=$ Fiscal Conservatism.

Figure 2. Correlation matrix for Study 2 data. On the top right are displayed the scatterplots and regression fit lines for the relationships among the variables measured on Study 2. Along the diagonal are displayed the histograms and density plots for each of the variable. On the bottom left are displayed the posterior distributions for the parameter $\rho$ and $\tau$ under the alternative hypothesis using a Beta prior of width $=0.5$. TDD.pat $=$ Pathogen Subscale of the Three Domains of Disgust; BODS = Body Odour Disgust Scale; RWA = Right Wing Authoritarianism; DSR = Disgust Sensitivity Revised; PVD.germ $=$ Germ aversion subscale of the Perceived Vulnerability to Disease.

Figure 3. Correlation matrix for Study 3 data. On the top right are displayed the scatterplots and regression fit lines for the relationships among the variables measured on Study 2. Along the diagonal are displayed the histograms and density plots for each of the variable. On the bottom left are displayed the posterior distributions for the parameter $\rho$ and $\tau$ under the alternative hypothesis using a Beta prior of width $=0.5$. BODS $=$ Body Odour Disgust Scale; RWA $=$ Right Wing Authoritarianism; SDO = Social Dominance Orientation; Att. Clinton = Positive attitudes towards Hillary Clinton; Att. Trump = Positive attitudes towards Donald Trump.

Figure 4. Study 3. Mediation analysis. Right Wing Authoritarianism (RWA) as a mediator of the effect of Body Odour Disgust Sensitivity (BODS) on attitudes towards Donald Trump. 
Values represent standardized parameter estimates for each path. Along the path from BODS to attitudes towards Trump the numbers in parentheses represent the coefficients when RWA was entered into the analyses. Dashed line indicates that the direct path is significantly mediated by the indirect path (i.e., its estimated confidence intervals do not include zero). 


\section{Bibliography}

1 Schaller, M. 2006 Parasites, behavioral defenses, and the social psychological mechanisms through which cultures are evoked. Psychol Inq. 17, 96-101.

2 Schaller, M., Duncan, L. A. 2007 The Behavioral Immune System Its Evolution and Social Psychological Implications. Syd Sym Soc Psychol. 293-307.

3 Oaten, M., Stevenson, R. J., Case, T. I. 2009 Disgust as a Disease-Avoidance Mechanism. Psychol. Bull. 135, 303-321. (10.1037/a0014823)

4 Schaller, M., Park, J. H. The Behavioral Immune System (and Why It Matters). Current directions in psychological science 2011:99-103.

5 Rozin, P., Haidt, J., McCauley, C. R. 2008 Disgust. In Handbook of emotions. (ed.^eds. M. Lewis, J. M. Haviland-Jones, L. F. L. Barrett), pp. 757-776. New York: Guildford Press.

6 Curtis, V., Aunger, R., Rabie, T. 2004 Evidence that disgust evolved to protect from risk of disease. Proceedings of the Royal Society B-Biological Sciences. 271, S131-S133. (10.1098/rsbl.2003.0144)

7 Schaller, M., Park, J. H. 2011 The Behavioral Immune System (and Why It Matters). Current directions in psychological science. 20, 99-103. (10.1177/0963721411402596) 8 Kurzban, R., Leary, M. R. 2001 Evolutionary origins of stigmatization: The functions of social exclusion. Psychol. Bull. 127, 187-208. (10.1037//0033-2909.127.2.187)

9 Crawford, J. T., Inbar, Y., Maloney, V. 2014 Disgust sensitivity selectively predicts attitudes toward groups that threaten (or uphold) traditional sexual morality. Personality and Individual Differences. 70, 218-223. (Doi 10.1016/J.Paid.2014.07.001)

10 Hodson, G., Costello, K. 2007 Interpersonal disgust, ideological orientations, and dehumanization as predictors of intergroup attitudes. Psychological Science. 18, 691-698. (Doi 10.1111/J.1467-9280.2007.01962.X)

11 Faulkner, J., Schaller, M., Park, J. H., Duncan, L. A. 2004 Evolved disease-avoidance mechanisms and contemporary xenophobic attitudes. Group Process Interg. 7, 333-353. $(10.1177 / 1368430204046142)$

12 Duncan, L. A., Schaller, M., Park, J. H. 2009 Perceived vulnerability to disease: Development and validation of a 15-item self-report instrument. Personality and Individual Differences. 47, 541-546. (10.1016/j.paid.2009.05.001)

13 Navarrete, C. D., Fessler, D. M. T. 2006 Disease avoidance and ethnocentrism: the effects of disease vulnerability and disgust sensitivity on intergroup attitudes. Evol Hum Behav. 27, 270-282. (Doi 10.1016/J.Evolhumbehav.2005.12.001)

14 Inbar, Y., Pizarro, D. A., Knobe, J., Bloom, P. 2009 Disgust sensitivity predicts intuitive disapproval of gays. Emotion (Washington, DC). 9, 435-439. (10.1037/a0015960)

15 Schaller, M., Murray, D. R. 2008 Pathogens, personality, and culture: Disease prevalence predicts worldwide variability in sociosexuality, extraversion, and openness to experience. $J$. Pers. Soc. Psychol. 95, 212-221. (10.1037/0022-3514.95.1.212)

16 Fincher, C. L., Thornhill, R., Murray, D. R., Schaller, M. 2008 Pathogen prevalence predicts human cross-cultural variability in individualism/collectivism. $P$ R Soc B. 275, 12791285. (Doi 10.1098/Rspb.2008.0094)

17 Schaller, M. 2011 The behavioural immune system and the psychology of human sociality. Philosophical transactions of the Royal Society of London Series B, Biological sciences. 366, 3418-3426. (10.1098/rstb.2011.0029)

18 Ludeke, S. G., Krueger, R. F. 2013 Authoritarianism as a personality trait: Evidence from a longitudinal behavior genetic study. Pers Indiv Differ. 55, 480-484.

(10.1016/j.paid.2013.04.015) 
19 Ludeke, S., Johnson, W., Bouchard, T. J. 2013 "Obedience to traditional authority:" A heritable factor underlying authoritarianism, conservatism and religiousness. Pers Indiv Differ. 55, 375-380. (10.1016/j.paid.2013.03.018)

20 Ludeke, S., Krueger, B. 2013 Authoritarianism as a personality trait: Evidence from a longitudinal behavior genetic study. Behav Genet. 43, 530-530.

21 Altemeyer, R. A. 1998 The other "authoritarian personality". Advances in Experimental Social Psychology. 30, 47-91. (10.1016/S0065-2601(08)60382-2)

22 Duckitt, J. 2001 A dual-process cognitive-motivational theory of ideology and prejudice. Advances in experimental social psychology.

23 Smith, K. B., Oxley, D., Hibbing, M. V., Alford, J. R., Hibbing, J. R. 2011 Disgust Sensitivity and the Neurophysiology of Left-Right Political Orientations. Plos One. 6, (10.1371/journal.pone.0025552)

24 Terrizzi Jr, J. A., Shook, N. J., McDaniel, M. A. The behavioral immune system and social conservatism: a meta-analysis. Evolution and Human Behavior: Elsevier Inc. 2013:99108.

25 Navarrete, Fessler. 2006 Disease avoidance and ethnocentrism: the effects of disease vulnerability and disgust sensitivity on intergroup attitudes. Evol Hum Behav. 27, 13-13. (10.1016/j.evolhumbehav.2005.12.001)

26 Navarrete, C. D., Fessler, D. M. T., Eng, S. J. 2007 Elevated ethnocentrism in the first trimester of pregnancy. Evol Hum Behav. 28, 60-65. (10.1016/j.evolhumbehav.2006.06.002) 27 Hibbing, J. R., Smith, E. R., Alford, J. R. 2013 Predisposed: Liberals, conservatives, and the biology of political differences.: Routlege.

28 Hatemi, P., McDermott, R. 2012 Policing the Perimeter: Disgust and Purity in Democratic Debate. Ps-Polit Sci Polit. 45, 675-687. (10.1017/S1049096512000686)

29 Graham, J., Haidt, J., Nosek, B. 2009 Liberals and conservatives rely on different sets of moral foundations. J. Pers. Soc. Psychol. 96, 1029-1046.

30 Rozin, P., Haidt, J., Fincher, K. 2009 Psychology. From oral to moral. Science. 323, 11791180 .

31 Case, T. I., Repacholi, B. M., Stevenson, R. J. 2006 My baby doesn't smell as bad as yours: The plasticity of disgust. Evol Hum Behav. 27, 357-365.

32 Stevenson, R. J. 2009 An Initial Evaluation of the Functions of Human Olfaction. Chem. Senses. 35, 3-20. (10.1093/chemse/bjp083)

33 Curtis, V., Biran, A. 2001 Dirt, disgust, and disease - is hygiene in our genes? Perspect. Biol. Med. 44, 17-31.

34 Olsson, M. J., Lundstrom, J. N., Kimball, B. A., Gordon, A. R., Karshikoff, B., Hosseini, N., Sorjonen, K., Olgart Hoglund, C., Solares, C., Soop, A., et al. 2014 The Scent of Disease: Human Body Odor Contains an Early Chemosensory Cue of Sickness. Psychol Sci.

35 Shirasu, M., Touhara, K. 2011 The scent of disease: volatile organic compounds of the human body related to disease and disorder. J Biochem. 150, 257-266. (10.1093/jb/mvr090) 36 Tybur, J. M., Bryan, A. D., Magnan, R. E., Hooper, A. E. C. 2011 Smells Like Safe Sex: Olfactory Pathogen Primes Increase Intentions to Use Condoms. Psychological science : a journal of the American Psychological Society / APS. 22, 478-480.

(10.1177/0956797611400096)

37 Landy, J. F., Goodwin, G. P. 2015 Does Incidental Disgust Amplify Moral Judgment? A Meta-Analytic Review of Experimental Evidence. Perspectives on Psychological Science. 10, 518-536. (10.1177/1745691615583128)

38 Hatemi, P. K., Gillespie, N. A., Eaves, L. J., Maher, B. S., Webb, B. T., Heath, A. C., Medland, S. E., Smyth, D. C., Beeby, H. N., Gordon, S. D., et al. 2011 A Genome-Wide Analysis of Liberal and Conservative Political Attitudes. The Journal of Politics. 73, 271285. (10.1017/S0022381610001015) 
39 Liuzza, M. T., Olofsson, J. K., Sabiniewicz, A., Sorokowska, A. In Press Body odor trait disgust sensitivity predicts perception of sweat bio-samples. . Chem. Senses.

40 Liuzza, M. T., Lindholm, T., Hawley, C., Gustafsson Senden, m., Ekström, I., Olsson, M. J., Larsson, M., Olofsson, J. K. 2016 The Body Odor Disgust Scale (BODS): Development and validation of a novel olfactory disgust assessment. Chem Senses.

(10.1093/chemse/bjw107)

41 Taub, A. The rise of American authoritarianism (March 1). Vox. 2016.

42 Paolacci, G., Chandler, J., Ipeirotis, P. G. 2010 Running experiments on Amazon

Mechanical Turk. Judgment and Decision Making. 5, 411-419.

43 Buhrmester, M., Kwang, T., Gosling, S. D. 2011 Amazon's Mechanical Turk: A New

Source of Inexpensive, Yet High-Quality, Data? Perspect Psychol Sci. 6, 3-5.

$(10.1177 / 1745691610393980)$

44 Berinsky, A. J., Huber, G. A., Lenz, G. S. 2012 Evaluating Online Labor Markets for

Experimental Research: Amazon.com's Mechanical Turk. Polit Anal. 20, 351-368.

(10.1093/pan/mpr057)

45 Shapiro, D. N., Chandler, J., Mueller, P. A. 2013 Using Mechanical Turk to Study Clinical Populations. Clinical Psychological Science. 1, 213-220.

46 Clifford, A. J., Jewell, L., Waggoner, P. D. 2015 Are samples drawn from Mechanical

Turk valid for research on political ideology? Research \& Politics. 2, 1-9.

$(10.1177 / 2053168015622072)$

47 Inbar, Y., Pizarro, D. A., Bloom, P. Conservatives are more easily disgusted than liberals. PCEM: Taylor \& Francis Group 2009:714-725.

48 Zakrisson, I. 2005 Construction of a short version of the Right-Wing Authoritarianism (RWA) scale. Personality and Individual Differences. 39, 863-872.

(10.1016/j.paid.2005.02.026)

49 Tybur, J. M., Lieberman, D., Griskevicius, V. 2009 Microbes, mating, and morality:

individual differences in three functional domains of disgust. J Pers Soc Psychol. 97, 103 122.

50 Skitka, L. J., Mullen, E., Griffin, T., Hutchinson, S., Chamberlin, B. 2002 Dispositions, scripts, or motivated correction? Understanding ideological differences in explanations for social problems. J. Pers. Soc. Psychol. 83, 470-487. (10.1037//0022-3514.83.2.470)

51 Graham, J., Nosek, B., Haidt, J. 2009 The Moral Stereotypes of Liberals and Conservatives.

52 Helzer, E. G., Pizarro, D. A. 2011 Dirty Liberals! : Reminders of Physical Cleanliness Influence Moral and Political Attitudes. Psychological Science. 1-6.

53 team, J. JASP: https://jasp-stats.org/. 8.1.1 ed 2016.

54 Dienes, Z. 2011 Bayesian Versus Orthodox Statistics: Which Side Are You On?

Perspectives on Psychological Science. 6, 274-290. (10.1177/1745691611406920)

55 Raftery, A. E. 1995 Bayesian model selection in social research. Sociol Methodol. 25, 111-163. (Doi 10.2307/271063)

56 Jarosz, A. F., Wiley, J. 2014 What Are the Odds? A Practical Guide to Computing and Reporting Bayes Factors. Journal of Problem Solving. 7, (10.7771/1932-6246.1167)

57 Jeffreys, H. 1961 Theory of probability. 3d ed. Oxford,: Clarendon Press.

58 McElreath, R. R. rethinking: Satistical Rethinking book package. 1.58 ed 2015.

59 McElreath, R. 2016 Statistical rethinking: A Bayesian course with examples in $R$ and Stan CRC Press.

60 Watanabe, S. 2010 Asymptotic Equivalence of Bayes Cross Validation and Widely

Applicable Information Criterion in Singular Learning Theory. J Mach Learn Res. 11, 35713594. 
61 Haidt, J., Mccauley, C., Rozin, P. 1994 Individual differences in sensitivity to disgust: A scale sampling seven domains of disgust elicitors. Personality and Individual Differences. 16, 701-713. (10.1016/0191-8869(94)90212-7)

62 Olatunji, B. O., Williams, N. L., Tolin, D. F., Abramowitz, J. S., Sawchuk, C. N., Lohr, J. M., Elwood, L. S. 2007 The Disgust Scale: Item analysis, factor structure, and suggestions for refinement. Psychological Assessment. 19, 281-297. (10.1037/1040-3590.19.3.281) 63 Duncan, L., Schaller, M., Park, J. 2009 Perceived vulnerability to disease: Development and validation of a 15-item self-report instrument. Pers Indiv Differ. 47, 541-546. 64 DeVellis, R. F. 2012 Scale development : theory and applications. 3rd ed. Thousand Oaks, Calif.: SAGE.

65 Pratto, F., Sidanius, J., Stallworth, L. M., Malle, B. F. 1994 Social dominance orientation: A personality variable predicting social and political attitudes. J. Pers. Soc. Psychol. 67, 741. 66 Sidanius, J., Pratto, F. 1999 Social dominance: An intergroup theory of social hierarchy and oppression. New York: Cambridge University Press.

67 Studies, A. N. E. ANES 2016 Pilot Study. 2016.

68 Dustin Tingley, T. Y. K. H. L. K. K. I. 2014 mediation: R Package for Causal Mediation Analysis. 1-39.

69 Imai, K., Keele, L., Tingley, D. 2010 A General Approach to Causal Mediation Analysis. Psychol Methods. 15, 309-334. (10.1037/a0020761)

70 Low, K. E. Y. 2006 Presenting the self, the social body, and the olfactory: Managing smells in everyday life experiences. Sociol Perspect. 49, 607-631. (DOI

10.1525/sop.2006.49.4.607)

71 de Groot, J. H. B., Smeets, M. A. M., Kaldewaij, A., Duijndam, M. J. A., Semin, G. R. 2012 Chemosignals Communicate Human Emotions. Psychol Sci.

72 de Groot, J. H. B., Smeets, M. A. M., Rowson, M. J., Bulsing, P. J., Blonk, C. G., Wilkinson, J. E., Semin, G. R. 2015 A Sniff of Happiness. Psychol Sci. 1-17.

73 de Groot, J. H., Semin, G. R., Smeets, M. A. 2017 On the Communicative Function of Body Odors. Perspect Psychol Sci. 12, 306-324. (10.1177/1745691616676599)

74 Terrizzi Jr, J. A., Shook, N. J., McDaniel, M. A. 2013 The behavioral immune system and social conservatism: a meta-analysis. Evol Hum Behav. 34, 99-108.

(10.1016/j.evolhumbehav.2012.10.003)

75 Richard, F. D., Bond, C. F., Stokes-Zoota, J. J. 2003 One hundred years of social psychology quantitatively described. Rev Gen Psychol. 7, 331-363. (10.1037/10892680.7.4.331)

76 Aaroe, L., Petersen, M. B., Arceneaux, K. 2017 The Behavioral Immune System Shapes Political Intuitions: Why and How Individual Differences in Disgust Sensitivity Underlie Opposition to Immigration. American Political Science Review. 111, 277-294.

(10.1017/S0003055416000770)

77 Jost, J., Federico, C., Napier, J. 2009 Political ideology: Its structure, functions, and elective affinities. Annu. Rev. Psychol. 60, 307-337.

78 Oaten, M., Stevenson, R. J., Case, T. I. 2011 Disease avoidance as a functional basis for stigmatization. Philosophical transactions of the Royal Society of London Series B,

Biological sciences. 366, 3433-3452. (10.1098/rstb.2011.0095)

79 Osmundsen, M., Petersen, M. B. 2016 Political Ideology and Precautionary Reasoning:

Testing the Palliative Function of Right-Wing Ideology on Obsessive-Compulsive

Symptoms. Social Cognition.

80 Tybur, J. M., Inbar, Y., Aaroe, L., Barclay, P., Barlow, F. K., de Barra, M., Becker, D. V., Borovoi, L., Choi, I., Choi, J. A., et al. 2016 Parasite stress and pathogen avoidance relate to distinct dimensions of political ideology across 30 nations. P Natl Acad Sci USA. 113, 1240812413. (10.1073/pnas.1607398113) 
81 Asbrock, F., Christ, O., Duckitt, J., Sibley, C. G. 2011 Differential Effects of Intergroup Contact for Authoritarians and Social Dominators: A Dual Process Model Perspective.

Personality and Social Psychology Bulletin. (10.1177/0146167211429747)

82 Inbar, Y., Pizarro, D., Iyer, R., Haidt, J. 2012 Disgust Sensitivity, Political Conservatism, and Voting. Social Psychological and ....

83 Tybur, J. M., Lieberman, D. 2016 Human pathogen avoidance adaptations. Curr Opin Psychol. 7, 6-11. (10.1016/j.copsyc.2015.06.005)

84 Haselton, M. G., Nettle, D. 2006 The paranoid optimist: An integrative evolutionary model of cognitive biases. Personality and Social Psychology Review. 10, 47-66. (DOI 10.1207/s15327957pspr1001_3)

85 Schaller, M., Neuberg, S. L. 2012 Danger, Disease, and the Nature of Prejudice(S). Adv Exp Soc Psychol. 46, 1-54. (10.1016/B978-0-12-394281-4.00001-5)

86 Stevenson, R. J. 2010 An initial evaluation of the functions of human olfaction. Chem. Senses. 35, 3-20. (10.1093/chemse/bjp083)

87 Olsson, M. J., Lundstrom, J. N., Kimball, B. A., Gordon, A. R., Karshikoff, B., Hosseini, N., Sorjonen, K., Hoglund, C. O., Solares, C., Soop, A., et al. 2014 The Scent of Disease Human Body Odor Contains an Early Chemosensory Cue of Sickness. Psychological Science. 25, 817-823. (Doi 10.1177/0956797613515681)

88 United Press International. UPI/CVoter poll: Hillary Clinton leads Donald Trump by 5 points. 2016 [cited 2017 20/04]; Available from:

http://www.upi.com/Top_News/US/2016/10/14/UPICVoter-poll-Hillary-Clinton-leadsDonald-Trump-by-5-points/5771476450376/

89 Espenshade, T. J., Hempstead, K. 1996 Contemporary American attitudes toward US immigration. Int Migr Rev. 30, 535-570. (Doi 10.2307/2547393)

90 Ahn, W. Y., Kishida, K. T., Gu, X. S., Lohrenz, T., Harvey, A., Alford, J. R., Smith, K. B., Yaffe, G., Hibbing, J. R., Dayan, P., et al. 2014 Nonpolitical Images Evoke Neural Predictors of Political Ideology. Curr. Biol. 24, 2693-2699. (Doi

10.1016/J.Cub.2014.09.050) 
BODY ODOUR DISGUST SENSITIVITY PREDICTS AUTHORITARIAN ATTITUDES.

Tables and figures

Table 1

Bayesian Correlation Table

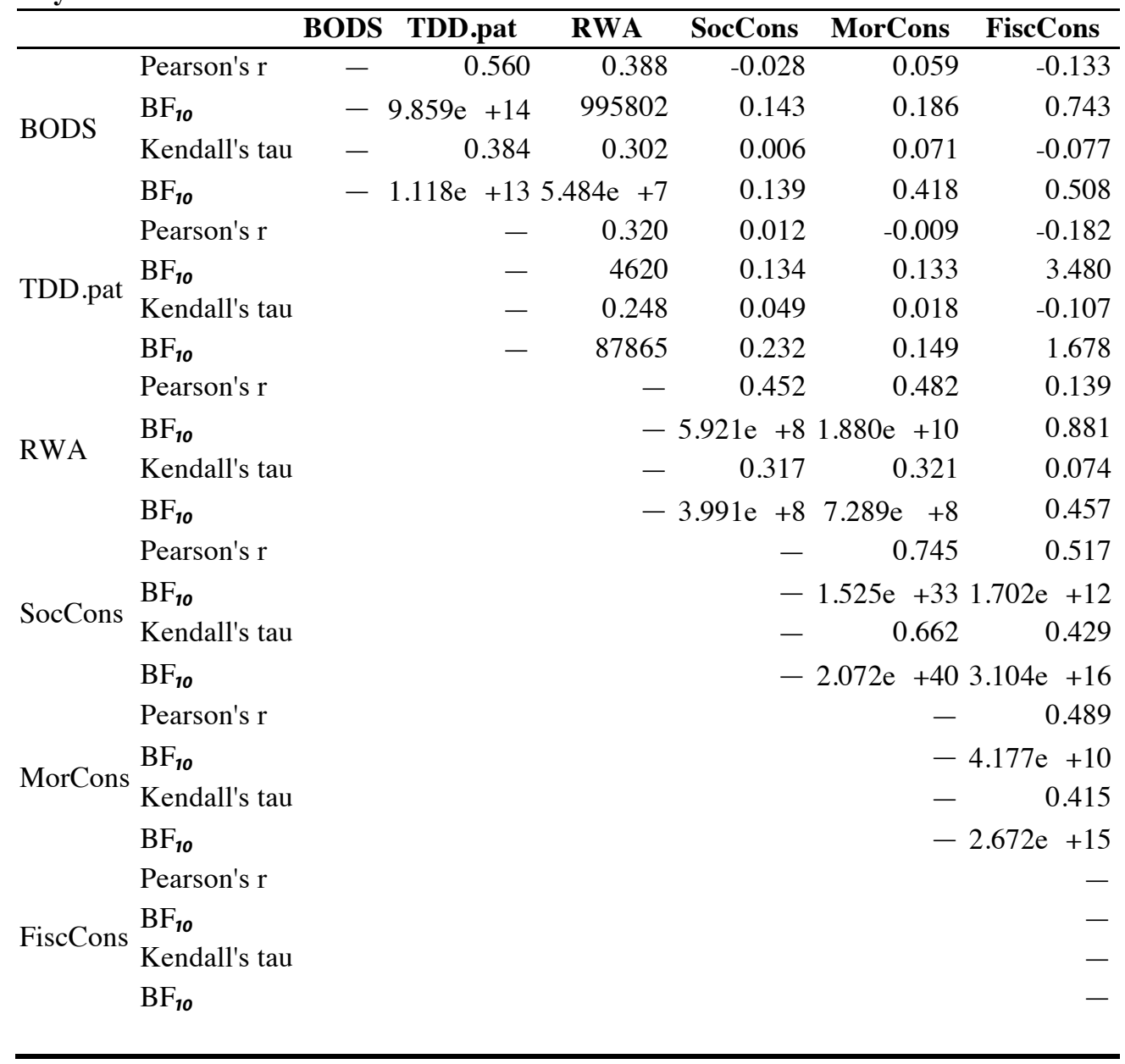


BODY ODOUR DISGUST SENSITIVITY PREDICTS AUTHORITARIAN ATTITUDES.

Figure 1
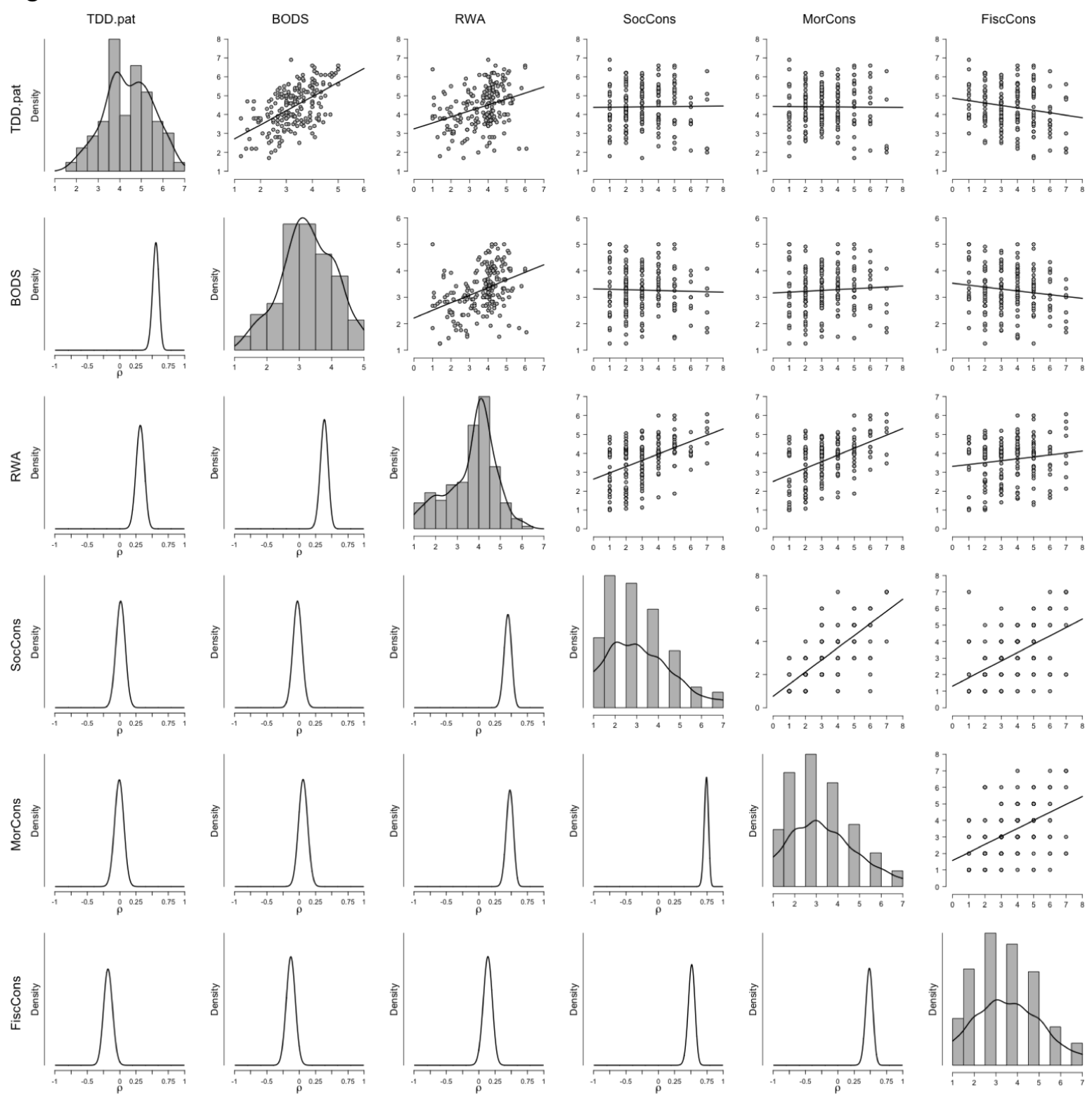
BODY ODOUR DISGUST SENSITIVITY PREDICTS AUTHORITARIAN ATTITUDES.

Table 2

\begin{tabular}{|c|c|c|c|c|c|c|}
\hline & $B$ & SE $B$ & WAIC & dWAIC & Weight & dSE \\
\hline Step1 & & & 500.11 & 4.67 & 0.06 & 6.54 \\
\hline Gender $(F=1)$ & -0.09 & 0.06 & & & & \\
\hline Age & 0.03 & 0.06 & & & & \\
\hline Edu & -0.02 & 0.06 & & & & \\
\hline $\begin{array}{l}\text { Ethnicity } \\
\text { (White = 1) }\end{array}$ & -0.57 & 0.06 & & & & \\
\hline TDD.pat & - & - & & & & \\
\hline BODS & - & - & & & & \\
\hline Step2 & & & 500.27 & 4.84 & 0.06 & 4.54 \\
\hline Gender ( $F=1)$ & -0.06 & 0.06 & & & & \\
\hline Age & 0.01 & 0.06 & & & & \\
\hline Edu & -0.01 & 0.06 & & & & \\
\hline $\begin{array}{l}\text { Ethnicity } \\
\text { (White = 1) }\end{array}$ & -0.53 & 0.07 & & & & \\
\hline TDD.pat & 0.09 & 0.07 & & & & \\
\hline BODS & - & - & & & & \\
\hline Step3 & & & 495.43 & 0.00 & 0.67 & 0.00 \\
\hline Gender $(F=1)$ & -0.07 & 0.06 & & & & \\
\hline Age & 0.02 & 0.06 & & & & \\
\hline Edu & 0.02 & 0.06 & & & & \\
\hline $\begin{array}{l}\text { Ethnicity } \\
\text { (White = 1) }\end{array}$ & -0.49 & 0.07 & & & & \\
\hline TDD.pat & - & - & & & & \\
\hline BODS & 0.17 & 0.06 & & & & \\
\hline Step4 & & & 497.76 & 2.33 & 0.21 & 0.53 \\
\hline Gender ( $F=1)$ & -0.07 & 0.06 & & & & \\
\hline Age & 0.01 & 0.06 & & & & \\
\hline Edu & 0.02 & 0.06 & & & & \\
\hline $\begin{array}{l}\text { Ethnicity } \\
\text { (White = 1) }\end{array}$ & -0.48 & 0.07 & & & & \\
\hline TDD.pat & 0.02 & 0.07 & & & & \\
\hline BODS & 0.16 & 0.07 & & & & \\
\hline
\end{tabular}


BODY ODOUR DISGUST SENSITIVITY PREDICTS AUTHORITARIAN ATTITUDES.

Table 3

Bayesian Correlation Table

\begin{tabular}{|c|c|c|c|c|c|c|}
\hline & & BODS & TDD.pat & DSR & PVD.germ & RWA \\
\hline \multirow{5}{*}{ BODS } & Pearson's $r$ & - & 0.469 & 0.480 & 0.259 & 0.241 \\
\hline & $\mathrm{BF}_{10}$ & - & $2.795 \mathrm{e}+7$ & $7.551 \mathrm{e}+7$ & 30.076 & 14.437 \\
\hline & Kendall's tau & - & 0.334 & 0.303 & 0.138 & 0.168 \\
\hline & $\mathrm{BF}_{10}$ & - & $3.000 \mathrm{e}+7$ & $1.097 \mathrm{e}+6$ & 4.077 & 19.430 \\
\hline & Pearson's r & & - & 0.506 & 0.168 & 0.137 \\
\hline \multirow{3}{*}{ TDD.pat } & $\mathrm{BF}_{10}$ & & - & $1.023 \mathrm{e}+9$ & 1.319 & 0.637 \\
\hline & Kendall's tau & & - & 0.385 & 0.160 & 0.096 \\
\hline & $\mathrm{BF}_{10}$ & & - & $1.621 \mathrm{e}+10$ & 12.581 & 0.752 \\
\hline \multirow{5}{*}{ DSR } & Pearson's r & & & - & 0.094 & 0.191 \\
\hline & $\mathrm{BF}_{10}$ & & & - & 0.290 & 2.512 \\
\hline & Kendall's tau & & & - & 0.040 & 0.124 \\
\hline & $\mathrm{BF}_{10}$ & & & - & 0.203 & 2.152 \\
\hline & Pearson's r & & & & - & 0.106 \\
\hline \multirow{3}{*}{ PVD.germ } & $\mathrm{BF}_{10}$ & & & & - & 0.353 \\
\hline & Kendall's tau & & & & - & 0.088 \\
\hline & $\mathrm{BF}_{10}$ & & & & - & 0.587 \\
\hline \multirow{4}{*}{ RWA } & Pearson's r & & & & & - \\
\hline & $\mathrm{BF}_{10}$ & & & & & - \\
\hline & Kendall's tau & & & & & - \\
\hline & $\mathrm{BF}_{10}$ & & & & & - \\
\hline
\end{tabular}


BODY ODOUR DISGUST SENSITIVITY PREDICTS AUTHORITARIAN ATTITUDES.

Figure 2
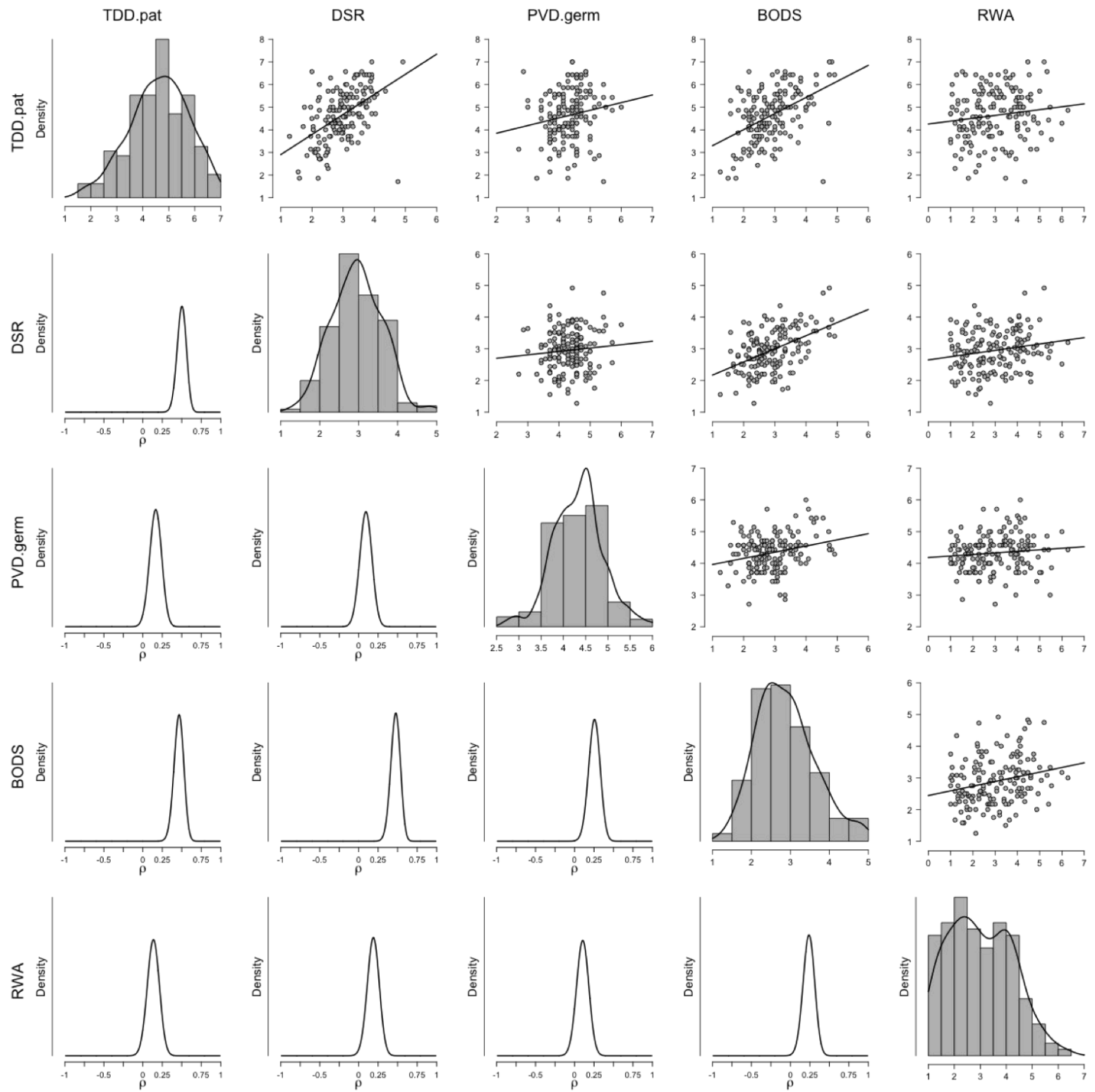
BODY ODOUR DISGUST SENSITIVITY PREDICTS AUTHORITARIAN ATTITUDES.

Table 4

\begin{tabular}{|c|c|c|c|c|c|c|}
\hline & B & SE $B$ & WAIC & dWAIC & Weight & dSE \\
\hline Step1 & & & 444.63 & 4.92 & 0.03 & 5.37 \\
\hline Gender ( $F=1)$ & 0.17 & 0.08 & & & & \\
\hline Age & 0.08 & 0.08 & & & & \\
\hline Edu & -0.21 & 0.08 & & & & \\
\hline Ethnicity (White $=1$ ) & -0.13 & 0.08 & & & & \\
\hline TDD.pat & - & - & & & & \\
\hline BODS & - & - & & & & \\
\hline Step2 & & & 439.72 & 0.00 & 0.39 & - \\
\hline Gender $(F=1)$ & 0.22 & 0.08 & & & & \\
\hline Age & 0.08 & 0.08 & & & & \\
\hline Edu & -0.19 & 0.08 & & & & \\
\hline Ethnicity (White $=1$ ) & -0.08 & 0.08 & & & & \\
\hline DS-R & 0.19 & 0.08 & & & & \\
\hline BODS & - & - & & & & \\
\hline Step3 & & & 440.90 & 1.18 & 0.21 & 5.07 \\
\hline Gender ( $F=1)$ & 0.17 & 0.08 & & & & \\
\hline Age & 0.08 & 0.08 & & & & \\
\hline Edu & -0.18 & 0.08 & & & & \\
\hline Ethnicity (White $=1$ ) & -0.08 & 0.08 & & & & \\
\hline DS-R & - & - & & & & \\
\hline BODS & 0.17 & 0.08 & & & & \\
\hline Step4 & & & 439.83 & 0.11 & 0.37 & 2.53 \\
\hline Gender (F = 1) & 0.21 & 0.08 & & & & \\
\hline Age & 0.08 & 0.08 & & & & \\
\hline Edu & -0.18 & 0.08 & & & & \\
\hline Ethnicity (White $=1$ ) & -0.06 & 0.08 & & & & \\
\hline DS-R & 0.14 & 0.08 & & & & \\
\hline BODS & 0.11 & 0.08 & & & & \\
\hline
\end{tabular}


Figure 3
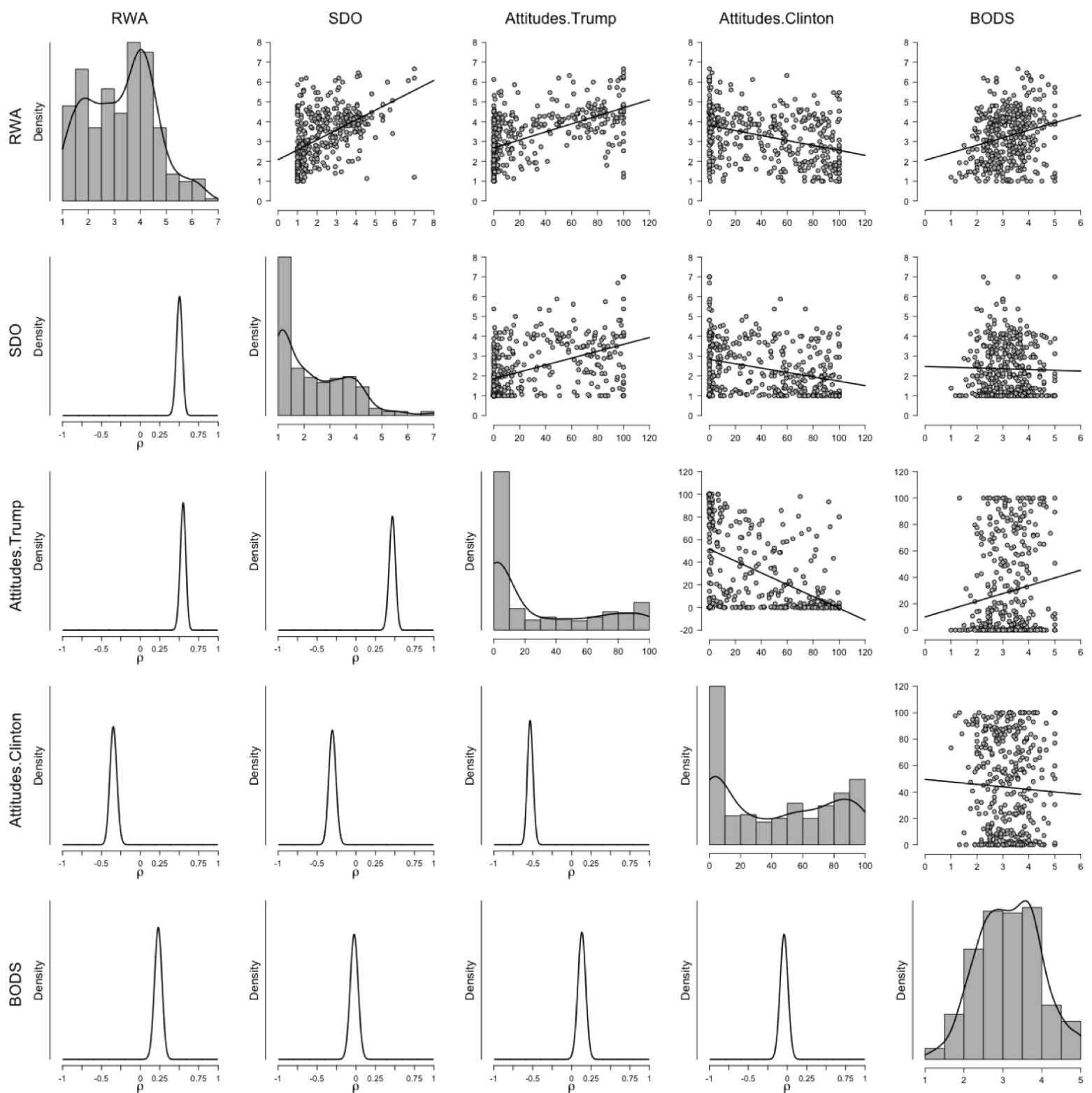
BODY ODOUR DISGUST SENSITIVITY PREDICTS AUTHORITARIAN ATTITUDES.

Table 5

Bayesian Correlation Table

\begin{tabular}{|c|c|c|c|c|c|c|}
\hline & & BODS & RWA & SDO & Attitudes.Trump & Attitudes.Clinton \\
\hline \multirow{5}{*}{ BODS } & Pearson's $r$ & - & 0.232 & -0.023 & 0.132 & -0.041 \\
\hline & $\mathrm{BF}_{10}$ & - & 3977 & 0.105 & 2.818 & 0.132 \\
\hline & Kendall's tau & - & 0.151 & -0.028 & 0.082 & -0.021 \\
\hline & $\mathrm{BF}_{10}$ & - & 1947 & 0.138 & 1.802 & 0.121 \\
\hline & Pearson's $r$ & & - & 0.505 & 0.552 & -0.348 \\
\hline \multirow{4}{*}{ RWA } & $\mathrm{BF}_{10}$ & & - & $3.406 \mathrm{e}+23$ & $1.725 \mathrm{e}+29$ & $5.479 \mathrm{e}+9$ \\
\hline & Kendall's tau & & - & 0.395 & 0.448 & -0.243 \\
\hline & $\mathrm{BF}_{10}$ & & - & $1.814 \mathrm{e}+28$ & $3.812 \mathrm{e}+36$ & $1.097 \mathrm{e}+10$ \\
\hline & Pearson's $r$ & & & - & 0.469 & -0.305 \\
\hline \multirow{4}{*}{ SDO } & $\mathrm{BF}_{10}$ & & & - & $5.245 \mathrm{e}+19$ & $1.275 \mathrm{e}+7$ \\
\hline & Kendall's tau & & & - & 0.378 & -0.209 \\
\hline & $\mathrm{BF}_{10}$ & & & - & $5.797 \mathrm{e}+25$ & $1.529 \mathrm{e}+7$ \\
\hline & Pearson's r & & & & - & -0.535 \\
\hline \multirow{3}{*}{ Attitudes.Trump } & $\mathrm{BF}_{10}$ & & & & - & $1.179 \mathrm{e}+27$ \\
\hline & Kendall's tau & & & & - & -0.416 \\
\hline & $\mathrm{BF}_{10}$ & & & & - & $2.181 \mathrm{e}+31$ \\
\hline \multirow{4}{*}{ Attitudes.Clinton } & Pearson's r & & & & & - \\
\hline & $\mathrm{BF}_{10}$ & & & & & - \\
\hline & Kendall's tau & & & & & - \\
\hline & $\mathrm{BF}_{10}$ & & & & & - \\
\hline
\end{tabular}


Figure 4

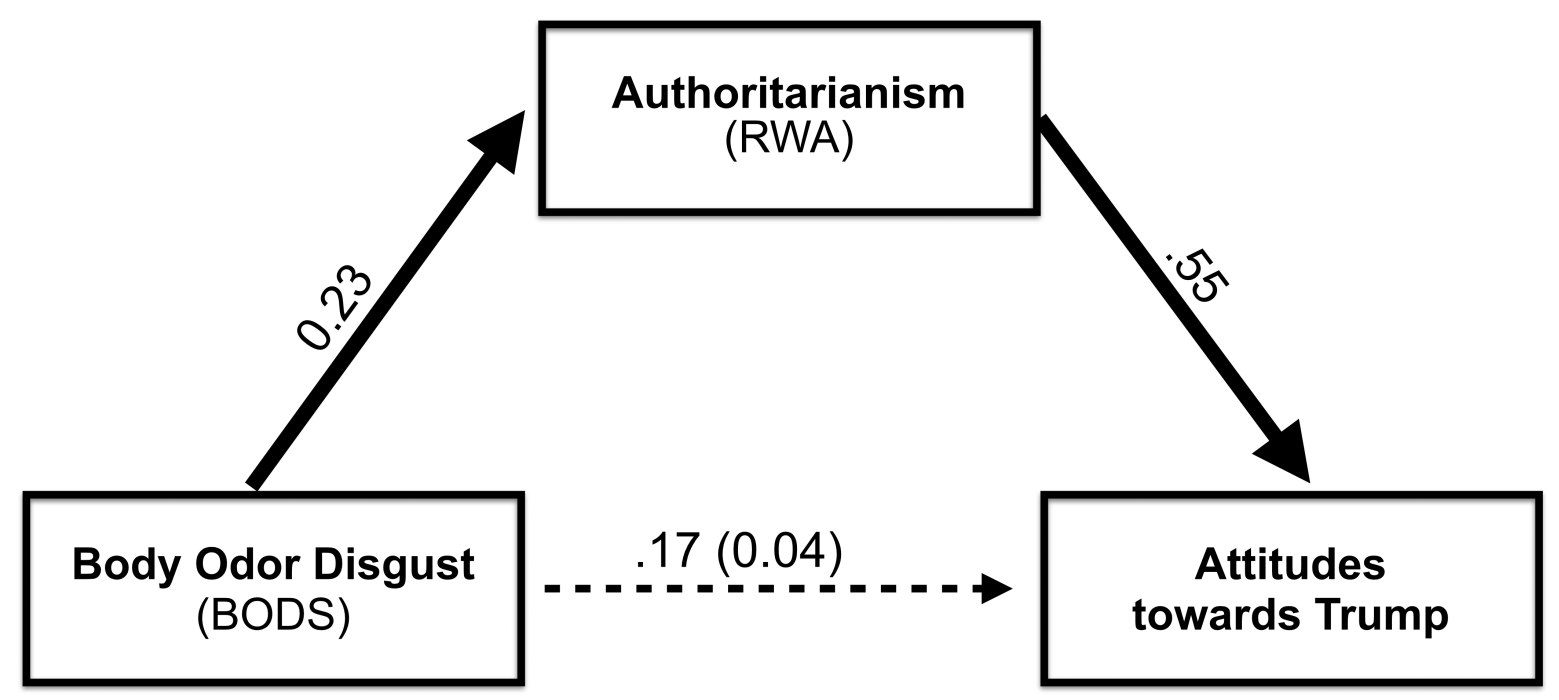

